British Journal of Psychiatry (1990), 157, 773-785

\title{
Correspondence
}

Editor: Ian Pullen

Contents: Insight and psychosis/The 'new crosscultural psychiatry'/Progesterone prophylaxis?/ Benzodiazepine withdrawal/ECT in neuroleptic malignant syndrome/Was Hitler a Christian?/The musical idiot savant/Anorexia nervosa and OCD/ Toad-lickers psychosis - a warning/Self-catering during rehabilitation/A Freudian lacuna?/Genetic origins of psychosis/Post-traumatic stress disorder/ Malaria presenting as atypical depression/Anorexia nervosa in people of Asian extraction/Temporal lobe in schizophrenia

\section{Insight and psychosis}

SIR: David's comments on 'Insight and psychosis' (Journal, June 1990, 156, 798-808), and those of other authors quoted by him, that "a surprising proportion of patients do possess insight", fully confirm my own experience.

In an essentially community-orientated adult psychiatric service, clinicians such as myself rely more than has traditionally been the case on patients assuming a considerable degree of responsibility for their illness and its treatment, and indeed for their general behaviour in a public context. It has been necessary, and increasingly a delightful surprise, to discuss fully with those we call 'long-term mentally ill' what Dr David has called their insight.

I have found that patients' comments are often at first misleading. One man in his fifties recently told me that he was definitely not mentally ill and did not require medication. This was our first meeting and he mistrusted me. Later, however, it transpired that he knew very well he had been suffering symptoms of schizophrenia much earlier in life and that depot neuroleptic medication controlled these symptoms more or less completely. He was anxious, however, that this admission would result in the removal of his Home Office Warrant, and that he would thereby lose his benefits and be forced to seek employment.

I was able to reassure this man that he would continue to receive benefits and could continue to attend the industrial workshop as before. The example demonstrates a further advantage for the clinician in exploring fully with the patient his or her insight. The therapeutic relationship deepens. Above all I have found in a number of cases that a patient's self-esteem rises spontaneously and almost palpably when their own grasp of their illness, often astonishingly sophisticated, is given professional credence.

May I therefore endorse Dr David's conclusions. May I suggest that psychiatrists do not wait for the results of formal research, and that they undertake informal research of their own with the very next long-term mentally ill patient they encounter. Too convincingly, I believe, have we been trained to attempt the imposition of our expectations on our patients, and we do so without recognising the burden, the awkwardness, the mistrust it places upon ourselves. Letting patients speak for themselves and take responsibility for themselves is a very liberating experience.

Finally, I wonder that Dr David omitted from his Appendix questions designed to clarify whether insight into another's illness might be preserved despite the loss of personal insight. Perhaps the publication in preparation (The Assessment of Insight by A. S. David \& G. Nestadt) will put this right.

L. D. CUlliford

Aldrington House

Hove Community Mental Health Centre

35 New Church Road

Hove BN3 4AG

SIR:-David's thought-provoking article (Journal, June 1990, 156, 798-808) seems to raise as many questions as it answers. My unease about it is due to the extent to which he assumes observer uniformity when assessing psychotic patients. He limits his use of the term 'insight' to the subject's appraisal of his mental state and his ability to label certain mental phenomena as morbid - "it simply requires the acceptance of personal illness affecting the mental apparatus". This seems fine at face value and even if the term 'illness' is dropped and 'change' used it still ignores the observer.

Alas, psychiatrists working in everyday practice are not as objective as we would like to think. Kreitman et al (1961) has shown that inter-rater 
reliability between observers for positive and easily defined symptoms is low. While standardised interviews do improve inter-rater reliability, the vast majority of ordinary psychiatric assessment is done on a more ad hoc basis and clearly insight is open to misinterpretation in this setting.

Secondly, the concept of pseudo-insight seems an important one. The hermeneutic value of an intellectual explanation of mental illness is important, but the form of an individual's appraisal of his mental disorder seems more significant than the content. Accepting treatment is one aspect of this, but perhaps an allowance needs to be made for the manner in which acknowledgement of medical illness comes about. There is a world of difference between the patient who says "I must be mad because you say so" and the resigned statement "you're right doctor, I'm breaking down again".

A third aspect relates to the psychiatrist's knowledge of mental disorder. His or her knowledge is generally by description (as opposed to by acquaintance). As insight is ultimately a clinical judgement of a patient by a doctor, what happens is for descriptive knowledge to be used to assess an experience that is classified as knowledge by acquaintance. There may not be a problem in this regard, but if knowledge by acquaintance is the route to insight, there seem no grounds on which to contradict a patient who tells his doctor "I have insight" when in reality he does not.

Department of Clinical Neurology

Alan Wear

Radcliffe Infirmary

Woodstock Road

Oxford $O X 26 H E$

\section{Reference}

Kretrman, N., Sainsbury, P., Morissey, J., et al (1961) The reliability of psychiatric assessment: an analysis. Journal of Mental Science. 107, 887-908.

SIR: We agree with David's contention (Journal, June $1990,156,798-808)$ that insight is best regarded as a multi-dimensional phenomenon. We would support Dr David's view that one such dimension is the ability of the patient to 'relabel' unusual mental events as pathological. However, we take the view that compliance with treatment should be seen not as a dimension of insight, but rather as a related phenomenon - as Lin et al (1979) have demonstrated, the correlation between insight and compliance is limited. This suggests that the schedule proposed by $\operatorname{Dr}$ David, which allows compliance itself to carry considerable weight, overemphasises the contribution of this variable to the core phenomenon.
The mechanisms underlying diminution of insight remain obscure, but are receiving increased attention. Insightlessness may be regarded as: (a) a normal phenomenon, insofar as many people demonstrate limited awareness of certain characteristics of their personality and behaviour; (b) a defence mechanism (denial); (c) a delusional phenomenon; (d) a feature of the schizophrenic defect state; and (e) a specific defect of cognition.

We have been attempting to operationalise the concept of insightlessness in schizophrenic patients. Given that direct measurement of the components of insightlessness is not possible, our proposed scale attempts to derive an overall measure, based on a semistructured interview. The scale distinguishes between attitudes to overall management and those to compliance with physical methods of treatment. Additionally, the scale permits measurement of behaviour in response to changes in psychopathology, perhaps the most important indicator of insight. An assessment of attitude to previous episodes of illness is included, an element which varies considerably between patients. Allowance is made for those subjects who reject the philosophical concept of mental illness, since it would be inappropriate to necessarily regard those as insightless. The scale measures insightlessness rather than insight, since the former has greater and more relevant clinical utility. (The schedule and score sheet are available from the authors.)

A pilot study of 13 patients fulfilling diagnostic criteria for schizophrenia indicates that scores derived from use of the schedule correlate well with global clinical impressions of insightlessness. In many of these patients, the degree of insight was not obviously correlated with the extent of delusional conviction.

The Three Bridges Regional Secure Unit

TIMOTHY LAMBERT

DAVID S. BALDWIN

St Bernard's Wing, Ealing Hospital

Uxbridge Road, Southall

Middlesex UBI $3 E U$

\section{Reference}

LIN, I. F., SPIGA, R. \& FoR TSCH, W. (1979) Insight and adherence to medication in chronic schizophrenia. Journal of Clinical Psychiatry, 40, 430-432.

AUTHOR'S REPLY: I am delighted that Dr Culliford finds my discussion on insight in accord with his clinical practice. The point about one patient's insight into another's delusions is a fascinating one as it suggests that the basis mechanisms of logical inference leading to a delusional misinterpretation may be 